\title{
Uncertain next steps
}

\author{
The future role of NASA in human space exploration remains economically uncertain. Should materials \\ scientists care?
}

On 2 September this year, the Materials Science Research Rack (MSRR-1) was installed on the International Space Station (ISS). A cooperative effort between NASA and ESA, the MSRR-1 will extend present efforts to look at the processing of a wide range of materials, from metals to ceramics, under microgravity conditions. By comparing their behaviour under microgravity with that on Earth, researchers hope to learn more about the mechanisms in operation during their processing, so improving them for applications on Earth.

Just over a week after the installation, on 11 September, the Review of US Human Space Flight Plans Committee, the so-called Augustine Committee, published their summary report ${ }^{1}$, which begins: "The US human spaceflight program appears to be on an unsustainable trajectory. It is perpetuating the perilous practice of pursuing goals that do not match allocated resources." The committee concludes that there is a shortfall in the NASA budget if it is to achieve its stated goals for human exploration of space beyond low-Earth orbit. Perhaps the most potent demonstration of the budget shortfall and insufficient planning comes from the Space Shuttle. For at least five years after it is decommissioned in 2011, NASA will be left without a way of shipping its astronauts to the ISS other than to rely on commercial or international partners while its successor is developed.

Having commissioned the committee's report to assess the present state of play at NASA, President Obama is faced with the decision of whether the US can afford its recommendation of an extra $\$ 3$ billion annually by 2014 on top of the $\$ 18.686$ billion annual budget already requested by NASA in 2010. Obama's pre-election vision for human exploration included going back to the Moon by 2020 , as Bush advocated while in office; Obama also expressed the desire for NASA to continue to have a strong role in Earthbound research. Without this extra funding, it is likely these aims would need to be severely moderated.

The committee also gives advice as to how NASA can achieve its goals while minimizing further funding requests. A tighter focus, in particular in terms of human exploration of Mars or other planets,

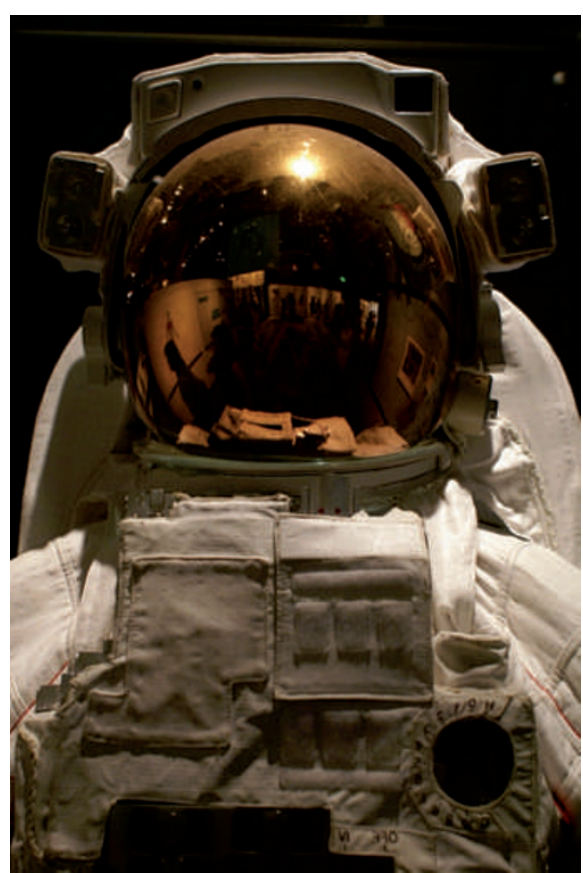

long list of success stories, from work on fuel cells to shape-memory alloys ${ }^{5}$.

But space agencies also give us, as scientists, more than that. NASA and ESA both act in the capacity of funding bodies in providing grants and stimulus for research. From their 2008 budget alone, NASA allocated $\$ 4.48$ billion of its funding to science research according to the American Association for the Advancement of Science, and was listed by them as one of the "primary federal support[s] for materials research" along with the NSF, DOE Office of Science, DOD, NIST and the NIH (ref. 6). And although this research is often focused in the first instance on materials and other technologies explicitly for space exploration, the advances in understanding and technology that accompanies it eventually benefit society as a whole. Cuts in this funding would be keenly felt.

Although the committee's report makes for sombre reading, there are some proposals that could be positive for materials scientists too. They recommend that the ISS's operational lifetime, after 25 years of assembly, is extended from 5 to 10 years, allowing more time for experiments on board - such as those using the MSRR-1. The request for more international collaboration, too, could mean benefits for scientists across the globe and not just in the US.

Sadly, the golden era for NASA feels long gone in the face of budget battles with healthcare and the financial crisis. Nevertheless, given Obama's pre-election ideology, the chances of space exploration being abandoned altogether are remote, and the ongoing value of materials science to NASA's goals is clear. Although adopting some or all of the Augustine Committee's recommendations for streamlining will certainly lead to some changes in focus in NASA's programme, materials science will always play a vital part in mankind's push, manned or otherwise, towards space. In fact, deeper space and planetary exploration just wouldn't be possible without it.

\footnotetext{
References

1. http://www.nasa.gov/offices/hsf/related_documents/summary_ report.html

2. Nature Mater. 3, 837 (2004).

3. http://www.sti.nasa.gov/tto/spinfaq.htm\#spinfaq12

4. http://technology.jsc.nasa.gov/success_stories.cfm

5. http://www.esa.int/SPECIALS/TTP2/SEMWLVRMTWE_0.html

6. http://www.aaas.org/spp/rd/rdreport2010/ch26.pdf
} 